\title{
ES2 as a Novel Verbascoside-Derived Compound in the Treatment of Cutaneous Wound Healing
}

\author{
Ilaria Crivellari ${ }^{1}$, Silvia Vertuani ${ }^{1}$, Yunsook Lim ${ }^{2}$, Franco Cervellati ${ }^{1}$, Anna Baldisserotto ${ }^{1}$, \\ Stefano Manfredini ${ }^{1}$ (D) and Giuseppe Valacchi ${ }^{1,2,3, *}$ \\ 1 Master Course in Cosmetic Science and Technology, Department Life Sciences and Biotechnology, \\ University of Ferrara, 44121 Ferrara, Italy; crvlri@unife.it (I.C.); vrs@unife.it (S.V.); crf@unife.it (F.C.); \\ bldnna@unife.it (A.B.); mv9@unife.it (S.M.) \\ 2 Deptartment of Food and Nutrition, Kyung Hee University, Seoul 130-701, Korea; ylim@khu.ac.kr \\ 3 Plants for Human Health Institute, Animal Sciences Department, NC Research Campus, NC State \\ University, KannapolisRaleigh, NC 28081, USA \\ * Correspondence: gvalacc@ncsu.edu; Tel.: +1-980-240-5008
}

Received: 29 September 2018; Accepted: 2 November 2018; Published: 7 November 2018

\begin{abstract}
Several pathologies are characterized by chronic wounds and often resistant to many of the common therapies, leading to chronic infections that can become even life-threatening for patients. For this reason, the identification of new products able to ameliorate the healing process is still an on-going research. Natural compounds have been used to improve skin conditions due to their dermo-cosmetic and therapeutic activities including anti-inflammatory, antioxidant and cell-migratory properties. Among these compounds, it has been recently demonstrated that Verbascoside, a phenyl propanoid glycoside widely used in the cosmetic field, can improve keratinocytes proliferation. Because of its high hydrophilic character, Verbascoside has a limited range of possible topical applications and the synthesis of ES2, a semi-synthetic derivative of Verbascoside was performed to bypass some of the drawback aspects of this molecule. In the present study, the wound healing properties of Verbascoside and ES2 were compared in both keratinocytes "in vitro" wound scratch and in wounded SKH1 mice. The results showed that both compounds were not cytotoxic and ES2 showed an efficient ability to promote the proliferation of human keratinocytes compared to Verbascoside. The findings were also confirmed in vivo but only at early time points ( $2 / 3$ days). Taken together, these data suggest that the Verbascoside-derivative ES2 could be considered a novel and promising candidate for the topical treatment of wounds.
\end{abstract}

Keywords: dermo-cosmetic; Cutaneous tissue; keratinocytes; SKH1; natural derivative; biotechnology platform

\section{Introduction}

Skin acts as a shield towards the external environment; therefore, its physical integrity is fundamental in order to accomplish its functions. Dermal and epidermal injuries, which compromise cutaneous physical barriers, lead to the activation of several cellular mechanisms with the purpose to restore the structural and functional integrity of the skin, activating the well-known process called wound healing [1].

Cutaneous wound healing is a complex persistent multi-step process involving overlapping stages of hemostasis, inflammation, proliferation and remodeling that in some cases can take years to be properly completed [2]. A variety of modulators including growth factors, cytokines, matrix metalloproteinases, cellular receptors and extracellular matrix components are involved in this challenging process [3]. 
When an injury occurs, the first phase of the healing process starts immediately to control the bleeding and to limit the spread of microorganisms within the body. The inflammatory phase, occurring simultaneously with hemostasis, is characterized by the increase of vascular impermeability and the release of several pro-inflammatory cytokines, chemokines, cationic peptides, proteases, reactive oxygen species, and growth factors in order to remove debris and kill bacteria [4].

After bleeding, the healing process involves the migration and the infiltration of inflammatory cells into the wound. Finally, during the remodeling phase, the new tissue is continuously remodeled until its composition and properties are close to those of the healthy tissue [2,4]. Keratinocyte migration and proliferation are fundamental steps and, indeed, the inability to re-epithelialize the tissues is a clear indicator of impaired wound healing [3].

Although minor injuries in healthy individuals generally heal well, larger injuries or the presence of a variety of pathophysiological factors including inflammation, infection, malnutrition, age, diabetes cause a failure in the healing process in ways that are still not completely defined by researchers [5-7].

In addition to the orthodox treatment, various alternative remedies have been tested to modulate the process of wound healing such as whey protein, topical application of HMGB1 protein in diabetic rats and mice, respectively, and also the installation of stem cells as the an application of negative pressure to the wound [2], but the actual treatment options for chronic wounds are still limited and unsuccessful and sometimes even have a very high manufacturing costs [4].

In this context, the interest in the use of natural and naturally derived compounds is gaining increasing interest in the dermo-cosmetic field. Significant efforts have been performed in the research aiming at novel production processes, extraction procedures, purification methods, and processing methodologies, including the use of cocoa, aloe, honey, oak bar extracts and also plant extracts [8].

Among those, some attention has been directed to Verbascoside, a phenylpropanoid glycoside characterized by cinnamic acid (C6-C3) and hydroxyphenylethyl (C6-C2) moieties that are attached to a $\beta$-glucopyranose via a glycosidic bond $[9,10]$. For instance, it has been shown that Verbascoside has anti-inflammatory [11], photoprotective [12] and antibacterial properties [13]. Especially the antioxidative mechanism is at the base of the claimed effects of this molecule, indeed, skin aging involves inflammatory responses, reduced amounts of antioxidants, degradation of collagen, MMP generation and impaired wound healing.

The bioavailability and biotransformation of plant polyphenols in the skin upon topical application are completely different from the process that takes place upon ingestion. In fact, the highly effective physical barrier properties of the skin make the task of delivering molecules to the cutaneous tissues extremely complicated. This is the reason why all exogenous substances with low lipophilicities, such as Verbascoside, have limited capacities for skin permeation leading researchers to aim at increasing skin permeation and the transdermal delivery by its inclusion into liposomes or lipogels [14].

Since the high hydrophilic character of Verbascoside limits its use to several topical applications, in our previous work we were able to synthesize its new acyl derivative, that thanks to a lower hydrophilic profile might improve the interaction of this molecule with cutaneous tissues [15].

The aim of the present study was to compare the effect of Verbascoside and its derivative ES2 on the wound healing process by the use of in vitro and in vivo models.

\section{Materials and Methods}

\subsection{Cell Culture}

HaCaT cells were provided by Dr. F. Virgili (INRAN, Rome, Iatly) and cultured in a humidified $5 \% \mathrm{CO}_{2} 37^{\circ} \mathrm{C}$ incubator in high glucose Dulbecco's modified Eagle's medium (DMEM) (Sigma, Milan, Italy), supplemented with 10\% fetal bovine serum (FBS) (EuroClone, Milan, Italy), $100 \mathrm{U} / \mathrm{mL}$ penicillin (EuroClone), $100 \mu \mathrm{g} / \mathrm{mL}$ streptomycin and $2 \mathrm{mM}$ L-glutamine (EuroClone), as previously described [16]. 
After having reached the confluency, cells were seeded in 6 well plates and cultivated with DMEM supplemented with $2 \%$ fetal bovine serum, $2 \mathrm{mM}$ L-glutamine, $100 \mathrm{U} / \mathrm{mL}$ penicillin and $100 \mathrm{\mu g} / \mathrm{mL}$ streptomycin overnight then all the experiments were performed in $10 \%$ FCS supplemented cells.

\subsection{Cell Treatments}

Verbascoside was obtained from Buddleia davidii meristematic cells, using a sustainable biotechnology platform which employs an in vitro plant cell culture technology from the company IRB, Altavilla Vicentina, Italy.

Verbascoside and ES2 were dissolved in Ethanol and stored at $4{ }^{\circ} \mathrm{C}$. Later, to perform the experiments, the compounds were diluted in DMEM supplemented with $10 \%$ fetal bovine serum (FBS), $100 \mathrm{U} / \mathrm{mL}$ penicillin, $100 \mu \mathrm{g} / \mathrm{mL}$ streptomycin and $2 \mathrm{mM} \mathrm{L}$-glutamine to reach the dilution 1 , $10,50 \mu \mathrm{M}$. Than the cells were treated with these two compounds for $24 \mathrm{~h}$ in a humidified $5 \% \mathrm{CO}_{2}$ $37^{\circ} \mathrm{C}$ incubator.

\subsection{Cell Viability}

Viability studies were performed by measurement of LDH release and cytofluorimetric assay as previously described [17]. The LDH levels in the supernatant were calculated based on the kit instructions (EuroClone, Milan, Italy). All tests were performed in triplicate and assays were repeated five times independently. In addition, cell count by the use of "Countess TM Automated Cell Counter" was also performed.

\subsection{In Vitro Wound Healing Assay}

After the $24 \mathrm{~h}$ of treatment the adherent cell layer was scratched with a sterile pipette tip in order to mimic the wound in vitro [18]. Cellular debris were removed by washing off with DMEM and incubated at $37^{\circ} \mathrm{C} 5 \% \mathrm{CO}_{2}$. Images of the scratches were recorded in different areas, using a Carl Zeiss Axioplan 2 microscope equipped with the camera AxioCam HR CCD and the software AxioVision 3.1 (Carl Zeiss, Göttingen, Germany) at time points going from 0 to $24 \mathrm{~h}$. The width of the scratches was analyzed with ImageJ software.

\subsection{Animals}

Hairless female SKH-1 mice (6 weeks old) were purchased from Orient Bio Inc. (Gyeonggi-do, Korea) and lodged in individual plastic cages at temperature- and humidity-controlled conditions ( $22 \pm 1{ }^{\circ} \mathrm{C}, \mathrm{RH} 50-60 \%, 12 \mathrm{~h}$ light/dark cycle) with allowed access to distilled water and food. Mice were acclimated for 10 days before initiation of the treatment. Mice $(n=20)$ were divided in 4 groups, one group $(n=5)$ for each treatment. The animals were randomly selected before the experiments and they were used in accordance with animal protocols approved by the Kyung Hee University Institutional Animal Care and Use Committee.

\subsection{In Vivo Wound Healing Assay}

Mouse skin was pinched and folded on the dorsum (anaesthetization with isoflurane, sterile biopsy punch $3.5 \mathrm{~mm}$ diameter, Miltex Instrument Company, York, PA, USA), below the shoulder so as to obtain six circular wounds identical in size, as previously described [19]. This area was selected for wounding as it cannot be reached by the mice thereby preventing self-licking and wound irritation. Wounds in individual mouse were photographed digitally every day, beginning on the day of wounding (d0) with a standard dot equivalent to the initial wound area placed beside the wound. The quantification of wound closure was performed as previously described [20]. Wound closure was quantified by Canvas 11SE software (Deneba, Miami, FL, USA). The rate of wound closure was expressed as the \% ratio of wound area (each day after wounding) compared with the initial wound 
area. Decreased wound ratio indicates the amelioration of wound closure. Eight microliters of each compound were applied daily on the corresponding wound.

\subsection{Statistical Analysis}

Statistical analyses were performed using two-way ANOVA followed by Bonferroni's multiple comparison test. A $p$-value $<0.05$ was considered significant. Data are reported as mean $\pm \mathrm{SEM}$. Exact $p$-values are indicated in the figure legends.

\section{Results}

\subsection{Effect of Verbascoside and ES2 on Cell Viability}

To evaluate the possible cytotoxic effect of Verbascoside and ES2 on HaCaT cells, cell counts and LDH assay were performed. As shown in Figure 1A, both Verbascoside and ES2 did not show any cytotoxic effects after $24 \mathrm{~h}$ of treatment at 1 and $10 \mu \mathrm{M}$ whereas at $50 \mu \mathrm{M}$ the treatments induced a circa $50 \%$ cytotoxicity in $\mathrm{HaCaT}$ cell line. The data were also confirmed by the LDH assay (Figure 1B), where it is possible to observe a significant increase in $\mathrm{LDH}$ release at the $50 \mu \mathrm{M}$ dose. Triton $\mathrm{X}$, the positive control, caused $100 \%$ cell death.

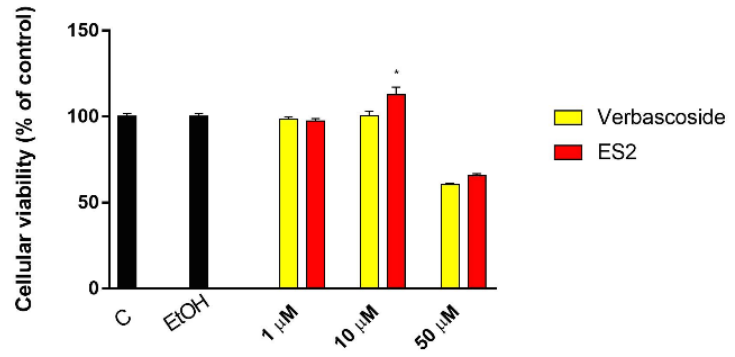

(A)

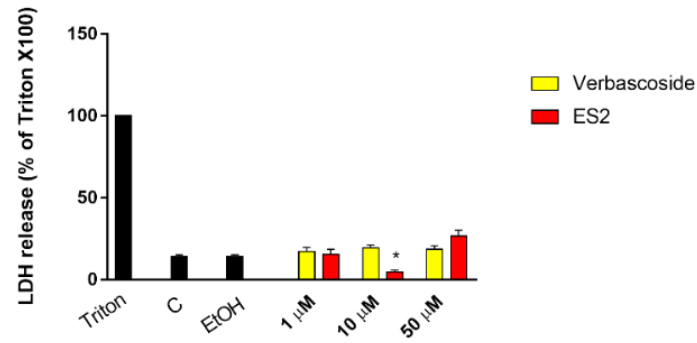

(B)

Figure 1. Verbascoside and ES2 didn't affect cell viability. (A) Cell viability of HaCaT cell line after treatment with Verbascoside and ES2 measured by Countess Automated Cell Counter, Invitrogen. The values are expressed as percentage compared with control $(* p=0.0406)$. The results are representative of three independent experiments. (B) Cytotoxicity of Verbascoside and ES2 in keratinocytes was measured by LDH release. The values are expressed as percentage compared to Triton $X\left(100 \%\right.$ of death cells) $\left.{ }^{*} p=0.0217\right)$. The results are representative of three independent experiments.

\subsection{Effect of Verbascoside and ES2 on In Vitro Wound Closure}

Based on the viability results, the following experiments were performed at the doses of 1 and $10 \mu \mathrm{M}$. As shown in Figure 2A, keratinocytes pre-treated with ES2 were able to achieve closure of the "in vitro" wound, much faster than Verbascoside. In particular, even if the two compounds at $1 \mu \mathrm{M}$ had similar effects, at higher doses $(10 \mu \mathrm{M})$ ES2 clearly improved wound closure of more than 2-fold. Quantification of the wound area at the different concentrations is depicted in Figure 2B,C, respectively.

\subsection{ES2 Induced an Higher Wound Closure after 2 Days of Topical Treatment}

To deeply evaluate the potential ability of these natural compounds in the wound healing process, in vivo experiments were carried out after pre-treatment with the compounds of interest. Figure 3 displays the area of the wound closure in animals treated with Verbascoside and ES2 during the 13 days of observation. At day 14, the wounds were almost all healed. As depicted in the figure, ES2 significantly improved wound closure in the first phase of the process (day 2) while at later time points no differences were observed. 


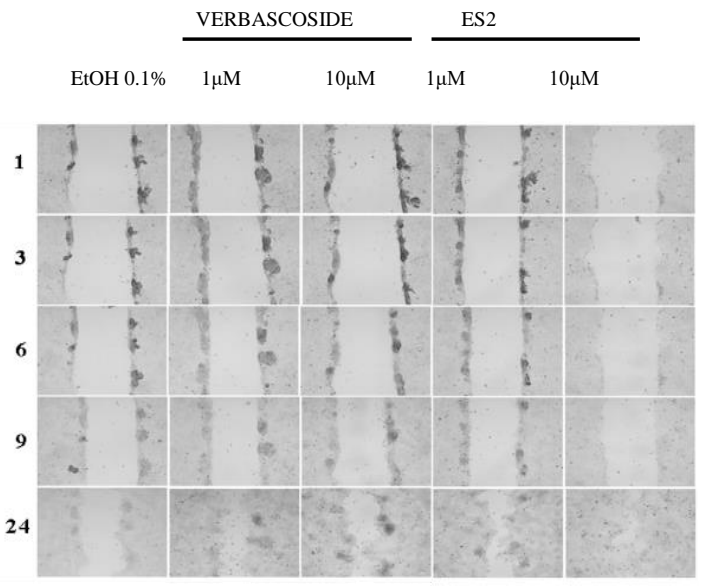

(A)

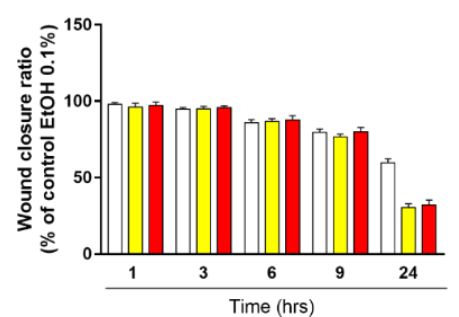

(B)

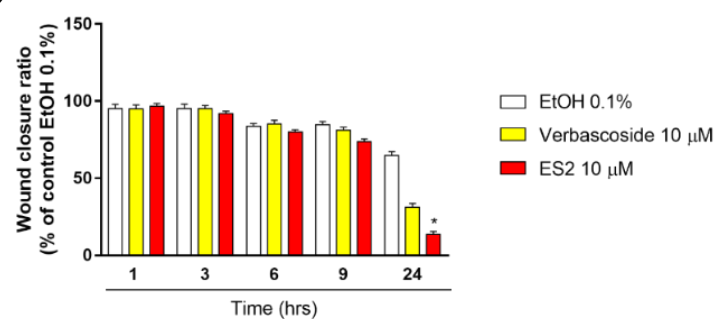

(C)

Figure 2. Effect of Verbascoside and ES2 on in vitro wound closure. (A) Representative images of wound closure in HaCaT cell line treated with 1 and $10 \mu \mathrm{M}$ of Verbascoside and ES2 (three independent experiments) for 1, 3, 6, 9, $24 \mathrm{~h}$. (B) Quantification of wound closure in HaCaT cell line treated with 1 $\mu \mathrm{M}$ of Verbascoside and ES2 (three independent experiments) for 1, 3, 6, 9, $24 \mathrm{~h}$. (C) Quantification of wound closure in $\mathrm{HaCaT}$ cell line treated with $10 \mu \mathrm{M}$ of Verbascoside and ES2 (three independent experiments) for $1,3,6,9,24 \mathrm{~h}\left({ }^{*} p=0.0002\right)$.

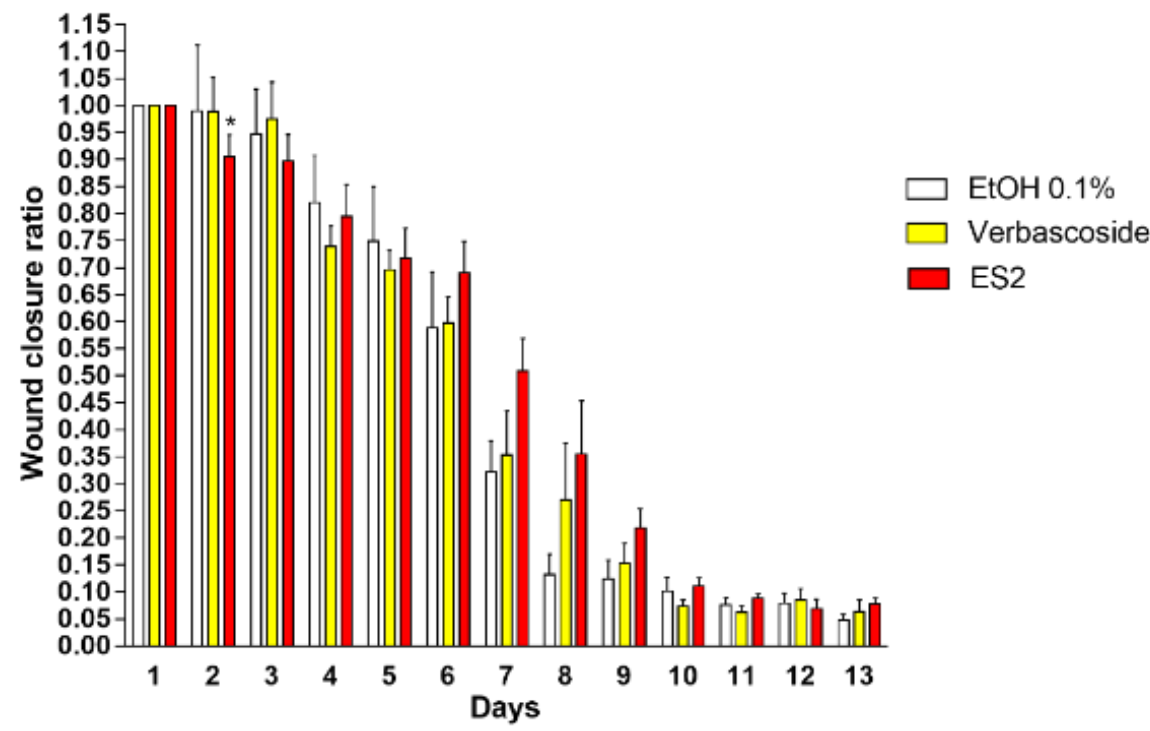

Figure 3. ES2 induced a higher wound closure after 2 days. Quantification of wound closure in SKH1 mouse model after topical application of Verbascoside and ES2 ( 5 animals per group) $\left({ }^{*} p<0.01\right)$.

\section{Discussion}

Improving wound healing is still a very large research program in the scientific world. Chronic ulcers have become a main challenge to healthcare systems worldwide. In the United States 
alone, these wounds affect circa $2.4-4.5$ million people [21,22]. Chronic ulcers in the low extremities (foot and leg) occur in many adults with vascular disease or diabetes and are attributed to chronic venous insufficiency, arterial disease, prolonged pressure, or neuropathy. These open wounds can take over a year to heal and can lead to loss of function, decreased quality of life, and can be significant causes of morbidity [23] being associated with a high treatment costs burden of diabetic foot ulcers for medical care and private insurers [24]. Some general features present in chronic wounds include prolonged or excessive inflammation, persistent infections, formation of drug-resistant microbial biofilms, and the inability of dermal and/or epidermal cells to respond to reparative stimuli $[25,26]$. Understanding and addressing the challenges in the treatment of chronic wounds will lead to a better clinical outcome (faster and more durable wound closure), resulting in improved patient quality of life and reduced healthcare costs. Several models have been developed from simpler cell co-culture models to 3D model and animal and human studies with the aim to better understand the mechanisms involved in cutaneous wound healing [27]. Although several advanced therapies have been developed and tested in order to prevent delayed healing and improve the healing process, there is still no strong solid evidence in humans able to define a clear treatment for chronic wound healing $[3,4]$. Duirng the past decade several groups have been interested in improving the healing properties of natural compounds, such as ozonated sesame oil [20,28] as wells as rottlerin [18], curcumin [29] and propoli [30].

Herbal-derived compounds are among the most commonly used therapies for the treatment of skin lesions, including the application of herbal preparations containing biologically active compounds that could stimulate the healing process [4]. Among those, we need to mention Verbascoside, a phenylpropanoide glycoside that was first isolated from mullein but can be found in several other plant species [31].

Verbascoside used in our experiments was extracted from butterfly bush Buddleia davidii, a shrub in the Buddlejiaceae family widely used as an ornamental plant and known for their wound healing, anti-inflammatory, diuretic, anti-allergic detergent, antiviral, antibacterial, photo and neuroprotective properties $[15,31]$.

The Buddleja davidii extract can be found at very high concentrations, approximately $80 \%$, in cell cultures deriving from a biosustainable biotechnology platform, which employs an in vitro plant cell culture technology leading to extracts with high levels of secondary metabolites [32].

A recent paper published by Sperotto et al. [33] highlighted the role of PAHE, the extract from Plantago australis that contains Verbascoside, in promoting wound healing in both in vitro and in vivo model after gavage administration. In the mentioned work, the authors were able to confirm our data in terms of keratinocytes migration improvement after Verbascoside treatment suggesting that Verbascoside can possibly improve cellular proliferation. Although redox signaling has been shown to be essential for correct wound closure, an overwhelming exposure to oxidative stress can impair this process [19]. Sperotto et al. were able to demonstrate that Verbascoside treatment increases catalase levels leading to a lower grade of oxidative stress and therefore ameliorates wound closure. Although in our study the levels of oxidative markers were not analyzes it is possible that also in our system the effect of Verbascoside and its derivative in improving wound healing could be a consequence of their ability to modulate the redox state of the cells.

Despite the claimed antioxidant activity, the highly hydrophilic character of the active ingredient represents a limit for its application in different types of formulations. It has been shown that Verbascoside has neuropathic activity [34] and wound healing properties in corneal epithelia when delivered in a lyposome system [35]. In the present work we tested Verbascoside Pentapropionate (ES2) a more lipid-soluble Verbascoside formulation that has been previously synthetized in our laboratory [15].

The aim of our study was to evaluate the wound healing properties of ES2 and Verbascoside in $\mathrm{HaCaT}$ cells line and in an SKH1 mouse model. 
The results obtained demonstrated that human keratinocytes treated with ES2 are able to significantly ameliorate the healing process of the wound compared to Verbascoside.

To avoid a possible cytotoxic effect on $\mathrm{HaCaT}$ cells, the cytotoxicity of these substances was tested. Cell count revealed no cytotoxicity for 1 and $10 \mu \mathrm{M}$ doses for both ES2 and Verbascoside, whereas cellular viability was affected with doses above $50 \mu \mathrm{M}$, most likely as a consequence of modification of cellular redox homeostasis.

Interestingly, ES2 at $10 \mu \mathrm{M}$ seemed to increase the cellular viability of keratinocytes, compared to Verbacoside although at this time we are not able to define the mechanism involved in this effect. This result was confirmed and strengthened by an LDH assay, which revealed no significant release of lactate dehydrogenase enzyme in the media after pre-treatment of $\mathrm{HaCaT}$ with Verbascoside and ES2.

After evaluatin the non-cytotoxic doses, we performed a "scratch wound" model in keratinocytes [18]. Although both substances were able to ameliorate the healing of the wound, ES2 showed a more evident effect already a $10 \mu \mathrm{M}$. This interesting result gave us the idea to test the compound also in an in vivo model. We found that the topical preparation containing the functional ingredient ES2 applied on the site of the biopsy increased the healing at days 2 and 3 compared to the Verbascoside.

A reason for the higher ability of ES2 to stimulate the healing could lie in its claimed anti-inflammatory properties and proliferation activity and its higher solubility [36,37]. In this regard, an interesting paper from Pastore et al. suggested that Verbascoside is able to perturb the pathway of epidermal growth factor (EGFR) in normal human epidermal keratinocytes (NHEK). Moreover, it can inhibit inflammatory responses in NHEK by downregulating both nuclear factor kappa-light-chain-enhancer of activated B cells $(\mathrm{NF} \kappa \mathrm{B})$ and activator protein 1 (AP-1) DNA binding.

In addition, the anti-inflammatory abilities of the tested compounds were also suggested by Sperotto et al. 2018 [33] as Verbascoside was able to reduce the levels of several inflammatory mediators such as TNF $\alpha$, IL-6, IL-12p70, MCP-1 and IFN $\gamma$ in LPS activated cells. Although in the present study the anti-inflammatory properties of Verbascoside and ES2 were not evaluated it is possible to suggest that this effect is also involved in the end-point observed in this work.

\section{Conclusions}

Improving and bringing new technologies for the treatment of chronic wounds will lead to a better clinical outcome (faster and more durable wound closure), resulting in improving patient quality of life and reduced healthcare costs.

In our study, a new semi-synthetic extract, ES2, obtained from Buddleia davidii, seemed to have all the credentials to be proposed as new approach for cutaneous wound healing as demonstrated by in vitro and in vivo studies. More mechanistic and deeper investigations are needed to better characterize the intrinsic mechanisms involved in this process.

Author Contributions: Conceptualization, G.V., S.V. and S.M.; methodology, I.C., F.C. and Y.L.; software, G.V. and Y.L.; formal analysis, G.V. and Y.L.; investigation, G.V., S.M. and Y.L.; resources, G.V., Y.L. and A.B.; writing-original draft preparation, G.V. and I.C.; writing-review and editing, G.V.; supervision, G.V.; funding acquisition, G.V. and S.M.

Funding: This research received no external funding.

Conflicts of Interest: The authors declare no conflict of interest.

\section{References}

1. Gurtner, G.C.; Werner, S.; Barrandon, Y.; Longaker, M.T. Wound repair and regeneration. Nature 2008, 453, $14-321$. [CrossRef] [PubMed]

2. Kasuya, A.; Tokura, Y. Attempts to accelerate wound healing. J. Dermatol. Sci. 2014, 76, 169-172. [CrossRef] [PubMed]

3. Rousselle, P.; Braye, F.; Dayan, G. Re-epithelialization of adult skin wounds: Cellular mechanisms and therapeutic strategies. Adv. Drug Deliv. Rev. 2018. [CrossRef] [PubMed] 
4. Pereira, R.F.; Bártolo, P.J. Traditional Therapies for Skin Wound Healing. Adv. Wound Care 2016, 5, $208-229$. [CrossRef] [PubMed]

5. Eming, S.A.; Martin, P.; Tomic-canic, M.; Park, H.; Medicine, R. Wound repair and regeneration: Mechanism, signaling and translation. Sci. Transl. Med. 2014, 6. [CrossRef] [PubMed]

6. Harding, K.G.; Morris, H.L.; Patel, G.K. Clinical review Healing chronic wounds. BMJ 2002, 324, $160-163$. [CrossRef] [PubMed]

7. Eaglstein, W.H.; Falanga, V. Chronic Wounds. Surg. Clin. N. Am. 1997, 77, 689-700. [CrossRef]

8. Davis, S.C.; Perez, R. Cosmeceuticals and natural products: Wound healing. Clin. Dermatol. 2009, 27, 502-506. [CrossRef] [PubMed]

9. Dembitsky, V.M. Astonishing diversity of natural surfactants: 5. Biologically active glycosides of aromatic metabolites. Lipids 2005, 40, 869-900. [CrossRef] [PubMed]

10. Jiménez, C.; Riguera, R. Phenylethanoid glycosides in plants: Structure and biological activity. Nat. Prod. Rep. 1994, 11, 591-606. [CrossRef] [PubMed]

11. Speranza, L.; Franceschelli, S.; Pesce, M.; Reale, M.; Menghini, L.; Vinciguerra, I.; de Lutiis, M.A.; Felaco, M.; Grilli, A. Antiinflammatory effects in THP-1 cells treated with verbascoside. Phyther. Res. 2010, 24, 1398-1404. [CrossRef] [PubMed]

12. Pastore, S.; Potapovich, A.; Kostyuk, V.; Mariani, V.; Lulli, D.; de Luca, C.; Korkina, L. Plant polyphenols effectively protect $\mathrm{HaCaT}$ cells from ultraviolet $\mathrm{C}$-triggered necrosis and suppress inflammatory chemokine expression. Ann. N. Y. Acad. Sci. 2009, 1171, 305-313. [CrossRef] [PubMed]

13. Azaizeh, H.; Tafesh, A.; Najami, N.; Jadoun, J.; Halahlih, F.; Riepl, H. Synergistic antibacterial effects of polyphenolic compounds from olive mill wastewater. Evid. Based Complement. Altern. Med. 2011, 2011. [CrossRef]

14. Sinico, C.; Caddeo, C.; Valenti, D.; Fadda, A.M.; Bilia, A.R.; Vincieri, F.F. Liposomes as carriers for verbascoside: Stability and skin permeation studies. J. Liposome Res. 2008, 18, 83-90. [CrossRef] [PubMed]

15. Vertuani, S.; Beghelli, E.; Scalambra, E.; Malisardi, G.; Copetti, S.; Toso, R.D.; Baldisserotto, A.; Manfredini, S. Activity and stability studies of verbascoside, a novel antioxidant, in dermo-cosmetic and pharmaceutical topical formulations. Molecules 2011, 16, 7068-7080. [CrossRef] [PubMed]

16. Valacchi, G.; Rimbach, G.; Saliou, C.; Weber, S.U.; Packer, L. Effect of benzoyl peroxide on antioxidant status, NF-kappaB activity and interleukin-1alpha gene expression in human keratinocytes. Toxicology 2001, 165, 225-234. [CrossRef]

17. Valacchi, G.; Sticozzi, C.; Belmonte, G.; Cervellati, F.; Demaude, J.; Chen, N.; Krol, Y.; Oresajo, C. Vitamin C Compound Mixtures Prevent Ozone-Induced Oxidative Damage in Human Keratinocytes as Initial Assessment of Pollution Protection. PLoS ONE 2015, 10, e0131097. [CrossRef] [PubMed]

18. Valacchi, G.; Pecorelli, A.; Mencarelli, M.; Carbotti, P.; Fortino, V.; Muscettola, M.; Maioli, E. Rottlerin: A multifaced regulator of keratinocyte cell cycle. Exp. Dermatol. 2009, 18, 516-521. [CrossRef] [PubMed]

19. Lim, Y.; Phung, A.D.; Corbacho, A.M.; Aung, H.H.; Maioli, E.; Reznick, A.Z.; Cross, C.E.; Davis, P.A.; Valacchi, G. Modulation of cutaneous wound healing by ozone: Differences between young and aged mice. Toxicol. Lett. 2006, 160, 127-134. [CrossRef] [PubMed]

20. Valacchi, G.; Zanardi, I.; Lim, Y.; Belmonte, G.; Miracco, C.; Sticozzi, C.; Bocci, V.; Travagli, V. Ozonated oils as functional dermatological matrices: Effects on the wound healing process using SKH1 mice. Int. J. Pharm. 2013, 458, 65-73. [CrossRef] [PubMed]

21. Brownrigg, J.R.W.; Apelqvist, J.; Bakker, K.; Schaper, N.C.; Hinchliffe, R.J. Evidence-based management of PAD \& the diabetic foot. Eur. J. Vasc. Endovasc. Surg. 2013, 45, 673-681. [PubMed]

22. Richmond, N.; Maderal, A.; Vivas, A. Evidence-based management of common chronic lower extremity ulcers. Dermatol. Ther. 2013, 26, 187-196. [CrossRef] [PubMed]

23. Atherley, G. Occupational disease prevention in Canada. A change of direction? Ann. N. Y. Acad. Sci. 1989, 572, 200-206. [CrossRef] [PubMed]

24. Rice, J.B.; Desai, U.; Cummings, A.K.G.; Birnbaum, H.G.; Skornicki, M.; Parsons, N. Burden of venous leg ulcers in the United States. J. Med. Econ. 2014, 17, 347-356. [CrossRef] [PubMed]

25. Woo, K.; Ayello, E.A.; Sibbald, R.G. The edge effect: Current therapeutic options to advance the wound edge. Adv. Skin Wound Care 2007, 20, 99-117. [CrossRef] [PubMed]

26. Frykberg, R.G.; Banks, J. Challenges in the Treatment of Chronic Wounds. Adv. Wound Care 2015, 4, 560-582. [CrossRef] [PubMed] 
27. Wilhelm, K.P.; Wilhelm, D.; Bielfeldt, S. Models of wound healing: An emphasis on clinical studies. Skin Res. Technol. 2017, 23, 3-12. [CrossRef] [PubMed]

28. Valacchi, G.; Lim, Y.; Belmonte, G.; Miracco, C.; Zanardi, I.; Bocci, V.; Travagli, V. Ozonated sesame oil enhances cutaneous wound healing in SKH1 mice. Wound Repair Regen. 2011, 19, 107-115. [CrossRef] [PubMed]

29. Esposito, E.; Sticozzi, C.; Ravani, L.; Drechsler, M.; Muresan, X.M.; Cervellati, F.; Cortesi, R.; Valacchi, G. Effect of new curcumin-containing nanostructured lipid dispersions on human keratinocytes proliferative responses. Exp. Dermatol. 2015, 24, 449-454. [CrossRef] [PubMed]

30. Rosseto, H.C.; Toledo, L.A.S.; de Francisco, L.M.B.; Esposito, E.; Lim, Y.; Valacchi, G.; Cortesi, R.; Bruschi, M.L. Nanostructured lipid systems modified with waste material of propolis for wound healing: Design, in vitro and in vivo evaluation. Colloids Surf. B Biointerfaces 2017, 158, 441-452. [CrossRef] [PubMed]

31. Alipieva, K.; Korkina, L.; Orhan, I.E.; Georgiev, M.I. Verbascoside-A review of its occurrence, (bio)synthesis and pharmacological significance. Biotechnol. Adv. 2014, 32, 1065-1076. [CrossRef] [PubMed]

32. Mazzon, E.; Esposito, E.; di Paola, R.; Riccardi, L.; Caminiti, R.; Toso, R.D.; Pressi, G.; Cuzzocrea, S. Effects of verbascoside biotechnologically produced by Syringa vulgaris plant cell cultures in a rodent model of colitis. Naunyn. Schmiedebergs Arch. Pharmacol. 2009, 380, 79-94. [CrossRef] [PubMed]

33. De Moura Sperotto, N.D.; Steffens, L.; Veríssimo, R.M.; Henn, J.G.; Péres, V.F.; Vianna, P.; Chies, J.A.B.; Roehe, A.; Saffi, J.; Moura, D.J. Wound healing and anti-inflammatory activities induced by a Plantago australis hydroethanolic extract standardized in verbascoside. J. Ethnopharmacol. 2018, 225, 178-188. [CrossRef] [PubMed]

34. Isacchi, B.; Bergonzi, M.C.; Iacopi, R.; Ghelardini, C.; Galeotti, N.; Bilia, A.R. Liposomal Formulation to Increase Stability and Prolong Antineuropathic Activity of Verbascoside. Planta Med. 2017, 83, 412-419. [CrossRef] [PubMed]

35. Ambrosone, L.; Guerra, G.; Cinelli, M.; Filippelli, M.; Mosca, M.; Vizzarri, F.; Giorgio, D.; Costagliola, C. Corneal epithelial wound healing promoted by verbascoside-based liposomal eyedrops. Biomed. Res. Int. 2014. [CrossRef] [PubMed]

36. Lin, S.Y.; Makino, K.; Xia, W.; Matin, A.; Wen, Y.; Kwong, K.Y.; Bourguignon, L.; Hung, M.C. Nuclear localization of EGF receptor and its potential new role as a transcription factor. Nat. Cell Biol. 2001, 3, 802-808. [CrossRef] [PubMed]

37. Lo, H.W.; Hung, M.C. Nuclear EGFR signalling network in cancers: Linking EGFR pathway to cell cycle progression, nitric oxide pathway and patient survival. Br. J. Cancer 2006, 94, 184-188. [CrossRef] [PubMed] 